\title{
Ecologically based landscape pattern optimization in northwest of Beijing
}

\author{
YUE Depeng ${ }^{1}$, "WANG Jiping ${ }^{2}$, LIU Yongbing ${ }^{3}$, ZHANG Xiaoli ${ }^{1}$, LI Hailong ${ }^{4}$, \\ WANG $\mathrm{Jie}^{3}$
}

1. School of Forestry, Beijing Forestry Univ.; Key Laboratory of Forest Resources Cultivation and Conservation, Ministry of Education, Beijing 100083, China;

2. Research Center for Eco-Environmental Sciences, CAS, Beijing 100085, China;

3. Environmental Protection Research Institute of Light Industry, Beijing 100089, China;

4. The Graduate School of Landscape Architecture, Peking University, Beijing 100871, China

\begin{abstract}
Supported by the technologies of remote sensing (RS) and geographical information system (GIS), we chose northwest of Beijing as a study area and gave priority to understanding of the spatial-temporal characteristics of landscape pattern change through visually interpreted Landsat TM images of 1989, 1996 and 2005. It is believed that there were a series of landscape ecological problems caused by city expansion: landscape ecological connectivity was low; landscape structure was simplified; the fragmentation of green land patch was more obvious on the plain areas, moreover, spatial distribution of green land was unbalanced. For this reason, this study adopted accumulative cost distance model, combined with ecosystem services and spatial interactions of landscape types, analyzed the spatial difference of the ecological function and the compactness of landscape structure in the study area, and further discussed the landscape pattern optimization proposal. We find that it is essential to protect and establish ecological sources, to establish urban ecological corridors, and to establish ecological nodes at the landscape ecological strategic positions so as to intensify spatial relationships among landscape elements and maintain continuity of landscape ecological process and pattern in the course of city expansion. The methods and final results from this study are expected to be useful for landscape ecological planning in Beijing region.
\end{abstract}

Keywords: accumulative cost distance model; landscape pattern optimization; Beijing

\section{Introduction}

The reciprocal relationship between landscape pattern and ecological process is always the core content of landscape ecology (Forman, 1986; Xiao, 1999; Wu, 2002). Landscape pat-

Received: 2008-09-01 Accepted: 2009-01-12

Foundation: Program for New Century Excellent Talent in the University, No.NCET-06-0122; The National Water Special Project, No.2008ZX07526-002-02; Specific Financial Funds Project of Beijing Academy of Science and Technology (BJAST), Platform Construction for Typical Contaminated Soil Remediation Technology of Beijing (2008A-1); Plan Support for Innovative Team (2008A-6) of BJAST; NSFC, No.30871964; BJNSFC, No.4073036

Author: Yue Depeng (1963-), Ph.D and Associate Professor, specialized in desertification control, landscape ecology and land evaluation. E-mail: ydp bl@yahoo.com.cn

"Corresponding author: Wang Jiping, E-mail: wjpgis@gmail.com 
tern (sometimes referred to as landscape structure) refers to features associated with the physical distribution or configuration of patches within a landscape (McGarigal and Marks, 1995), which are different in size and shape in space owing to the interaction of various ecological activities (Ding, 2005). This kind of landscape structure is comprehensive characterization of landscapes heterogeneity under combined actions of nature factors and artificial factors in different scale, and determines the distribution pattern of resource and physics environment (Forman, 1989; Turner, 1993). The landscape spatial pattern not only affects ecological process (flows of materials, energy and species across landscapes), but also influences circulation and development of landscape ecological function. Conversely, the process can create, modify and maintain the landscape spatial patterns. Optimization of landscape patterns aims to build a kind of optimized landscape which supports certain ecosystem functions in an optimal way (Scppelt, 2003). Research into the spatial optimization of landscape pattern should be based on understanding of the relationships among landscape pattern, landscape function and landscape process, but the more important issue is how to maximize eco-efficiency and improve ecological safety of landscape (Han et al., 2005). Landscape pattern optimization plays important roles in anti-disturbance capability, recoverability, ecosystem stability and biological diversity (Turner, 1993). Thus, it is of paramount importance in both theory and practice to address the questions of landscape pattern optimization ( $\mathrm{Wu}, 2002)$. Along with the deep understanding of relationship between landscape pattern and ecological process, it is considered that research into the spatial optimization of landscape pattern for ecological processes may present a new and exciting direction for landscape ecology (Hof and Flather, 2007).

Landscape pattern is the core issue of landscape ecology, the goal of which is to analyze the ecological process by identifying the landscape pattern. Due to the fact of landscape ecological process is more connotative and sophisticated, whereas landscape pattern is more intuitive and exteriors, in landscape scale, the existing research result is difficult to reflect the corresponding relationship between pattern and process, and to further quantitative analysis of the effect of patterns on process. So, it makes the study of landscape pattern optimization has been a puzzle in ecology and geography (Wu, 2002). Landscape pattern optimization, in essence, is a problem of how to obtain a reasonable utilization of land with the help of landscape ecological principle (e.g., optimization of land use pattern, optimal landscape management, optimal landscape design and planning). At present, most of researches on landscape pattern optimization mainly focuses on aspects such as conceptual model, mathematics model and computer simulation at home and abroad, whose applications includes land use structure changes (Seppelt, 2002; Thomas, 2002), resources regulation and allocation (Kang, 1999), soil nutrient balance ( $\mathrm{Fu}, 1994)$ and spatial pattern designing of species activities, etc. (Yu, 1999; Vincent, 2000). But as a whole, it is still lack of applying the interaction principles of pattern and process to carry through the study on structure optimization of landscape. No breakthrough development was obtained in quantitative study and systemic analysis on change of landscape function and ecological responses of landscape pattern variability. In addition, the accomplishment and existing methods cannot satisfy concrete requirement of landscape ecological planning in the practical application, and it is difficult to solve the problem of regional ecological environment systemically.

As an important measurement index of pattern optimization, landscape connectivity has become a vital component in conservation science and land management planning, and 
landscape ecologists define landscape connectivity as the degree to which the landscape facilitates or impedes movement among resource patches (Taylor et al., 1993). With the fast development of economy and technology, the influence brought by various disturbance activities on landscape connectivity has become an important issue, particularly the influence of rapid urbanization process, which makes the landscape more fragmented and affects ecological services function of landscape (Zeng, 2000). Therefore, how to solve the conflict between urban development space and natural ecological space has been attracting more and more attention from geographers, planning masters and land managers (Yu, 1997; Yuan, 2003). However, facing up these problems, urban planning will be easy to get into trouble due to the difficulty of incorporating the strategies of landscape pattern optimization into the given spatial pattern. Furthermore, during the implementation of ecological measure, though the local spatial structure of landscape usually is considered, it is difficult to the internal relations among different ecosystems and the continuity of whole function process generally. So, based on ecological processes and comprehensive understanding of the relationships among pattern, function and process in landscape, it is highly necessary to identify and establish certain utmost important landscape elements which can control the ecological process to effectively improve the continuity of region ecological function because it will contribute to landscape ecological construction and urban sustainable development.

In this paper, we presented a new simplifying approach for exploring the optimization mode of a real landscape based on ecology on a large spatial scale. We chose the northwest of Beijing as a study area-one of the rapid urbanization regions in Beijing. First of all, landscape pattern indices were used to analyze dynamic change law of regional landscape pattern in recent decades, and the basic information of whole variation characteristics of land use pattern were obtained. Though this method is simple and feasible to acquire the dynamic change characteristic of landscape expediently, it is difficult to depict the correlation of landscape elements and the change characteristic of local landscape. Therefore, we established an accumulative cost distance model to analyze the spatial extension trend of ecological flow according to the principle that the movements of flow, energy and material in a landscape are related to some factors such as distance, time, impedance, etc. Supported by remote sensing (RS) and geographical information system (GIS), by analyzing spatial interactions of different functional landscape elements, the landscape units which remain to be optimized were determined based on the actuality characteristic of land use in the study area. Besides, through appraisal of the ecosystem services of different land use types, the ecological source patches were more scientifically determined based on quantitative assessment of the ecological function intensity of the study area, followed that, under the support of accumulative cost distance model, the ecological corridors and nodes were identified and established. In the end, landscape eco-network was built combined with landscape structure features of urban ecological infrastructure, and an optimized scheme of landscape pattern is proposed. The objective of this paper is to find optimum land-use patterns with respect to the spatial connectivity of ecology landscape by means of application of accumulative cost distance model to identify and build landscape elements which contribute positively to the development of the ecological process. 


\section{Study area and method description}

\subsection{Study area}

The study was carried out in the administrative districts of Yanqing and Changping in northwest Beijing, China (Figure 1). It covers an area of $3344.5 \mathrm{~km}^{2}$. The terrain in southeast is lower than in northwest. The elevation is between 250 and $2250 \mathrm{~m}$. The annual rainfall varies between 400 and $600 \mathrm{~mm}$, and the forest-cover rate in the study area reaches $60 \%$ before 2005. Main land use types in this region are forestland, cultivated land and urban and building land. This region is the first zone from which the wind-sand flow invades, and the desertification degree was relatively severe under the common action of natural factors and artificial factors. So it has always been one of the key regions for studying and combating sandy desertification. Rapid population growth, development and change in land use and land cover have become obvious features of the landscape because of the economic and cultural position, especially its political core status in China.

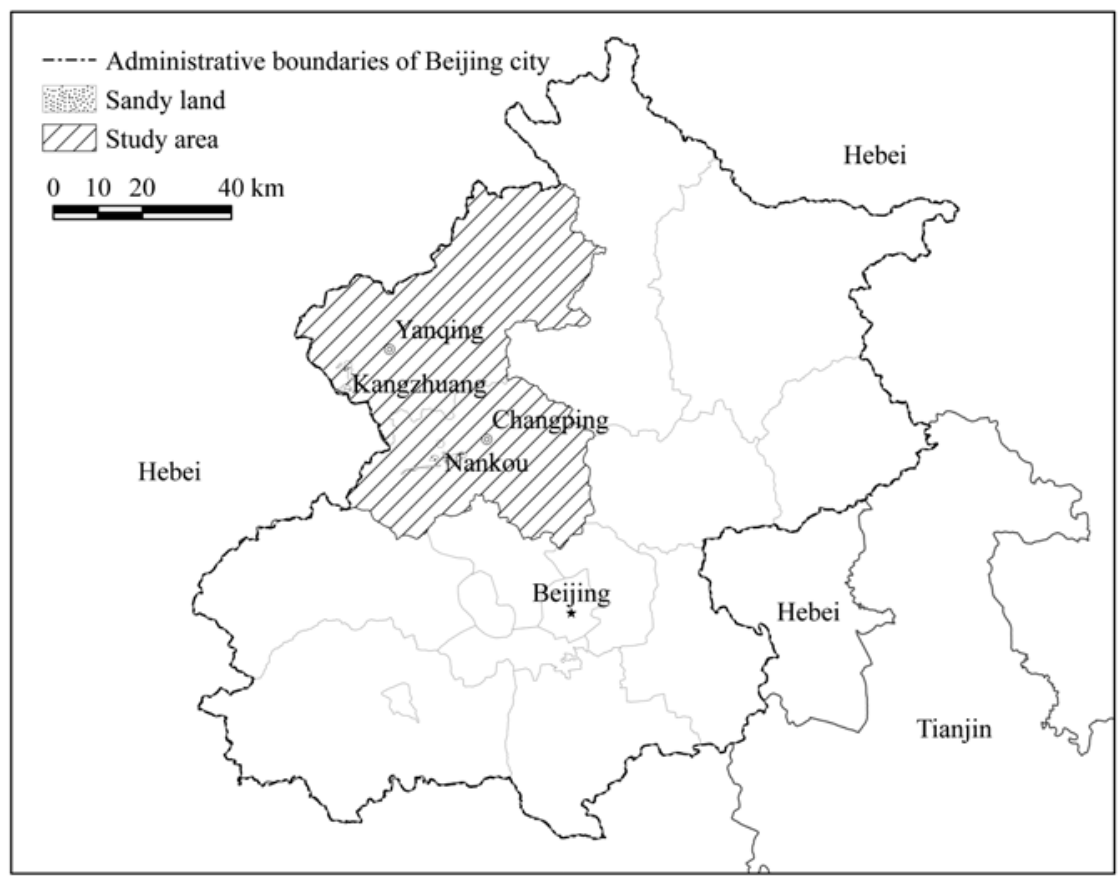

Figure 1 Location of northwest Beijing, China

\subsection{Data base}

The study area is a key region for ecological rehabilitation planning in Beijing. Nankou and Kangzhuang sandy lands are the largest area of wind-sand land in this region, thus, the sandy badland was also considered as a land use type to study. With the support of Arcgis 9.2 and ERDAS 9.1 software, land use data including 7 categories was available at a resolution of $30 \mathrm{~m}$ for three periods (1989, 1996 and 2005) (Figure 2). The study was mainly based on land use data from 2005. Land use data from the other two time periods was only used for analyzing dynamic change characteristics of landscape pattern. The land use classification is the result of a visual interpretation of data from different sources (Landsat TM satellite im- 
age, 1:100,000 topographic map and 1:4,000,000 administrative map). The topographic map and administrative map were imported as a background and combination with necessary field survey and validation. The Landsat TM image data were obtained from the Remote-Sensing Satellite Ground Station, Chinese Academy of Sciences. The topographic maps and administrative map were provided by Environmental \& Ecological Science Data Center for West China, National Natural Science Foundation of China. And the census data were obtained from Beijing Area Statistical Yearbook issued in 2004 (auxiliary information).
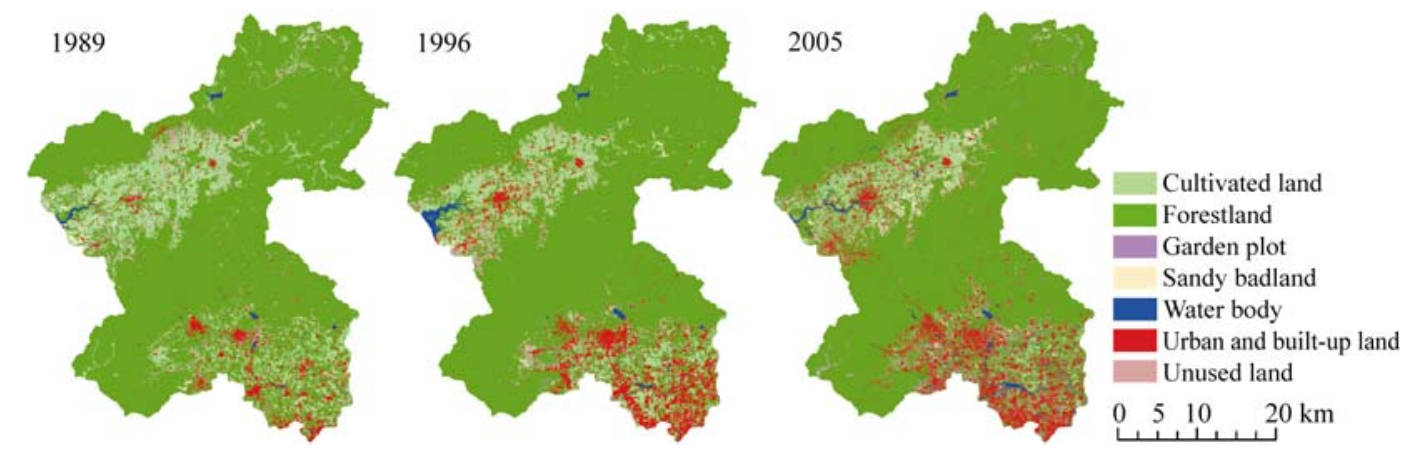

Figure 2 Land use pattern of the study area in 1989, 1996 and 2005

\subsection{Calculation and selection of landscape indices}

In this study, the land use data was exported in ArcGrid file format, the landscape indices were analyzed by using Fragatats 3.3 Software Package (McGarigal, 1995). In the computation of class-level metrics, the mean contiguity index (CONTIG_MN), patch density (PD), average patch area (AREA_MN) and mean patch shape index (SHAPE_MN) were calculated. In the computation of landscape-level metrics, the number of patches (NP), landscape fragmentation (F), dominance (D), Shannon diversity index (SHDI), Shannon evenness index (SHEI) and connectivity (C) were chosen and calculated.

\subsection{Accumulative cost distance model}

Landscape is a natural synthesis shaped and affected by the joint actions of climate, landform, relief, vegetation and human activities (He, 2007), which is a complex of geographically, functionally and historically interrelated ecosystems (Doing, 1997). Within a landscape, ecological process is the crucial factor that controls the stabilization of landscape function, and landscape structure influences processes such as the flow of energy, materials, and species between the ecosystems. So, we can use the principle of overcoming landscape resistance or paying the cost to depict effects of the pattern on ecological processes. According to landscape ecology, there always exist some landscape elements like waters, core patch of forest land and large area of grassland, which contribute positively to the development of the ecological processes (Chen, 2005). Therefore, based on the spatial analysis of 'cost-distance' extension of Arcgis, we formulated the accumulative resistance model in order to provide a characterization of the effects of resistance of the landscape on development of ecological flows in spatial surface. The model mainly involve source, effective distance, resistance of different landscape types, which is determined by the following formula: 


$$
C_{i}=\sum\left(D_{i} \times R_{j}\right) \quad(i=1,2,3, \ldots n ; j=1,2,3 \ldots, m)
$$

where $D_{i}$ is the effective geographical distance from source to an arbitrary cell $i, R_{j}$ is the resistance of a cell $j$ of a landscape type, $C_{i}$ is the accumulated resistance in cell $i$, and $n$ is the number of landscape cell.

The accumulative resistance model's essence is an integrated expression of accumulated cost distance, which is not the actual distance between two spatial landscape cells but describe the accumulative effect of the resistance in a certain spatial distance. To calculate the accumulative cost from each cell to the nearest source, the cost distance model needs a source layer and a resistance layer.

In this paper, the method of principles of graph theory was used to analyze the neighbor relationship of landscape unit (grid cell). The model is based on an eight-neighbour-cell algorithm, and the algorithm utilizes the node/link cell representation (Figure 3). In the node/link representation, each center of a cell is considered a node and each node is connected to its adjacent nodes by links. Every link has a resistance associated with it. The resistance is derived from the costs associated with the cells at each end of the link (from the cost surface) and from the direction of movement. The resistance value of each cell in the grid is based on the resistance value of the land cover type attributed, but can be refined in many different ways if necessary (Adriaensen et al., 2003). Thus, based on the graph theory, the accumulative cost to travel through each cell can be cal-

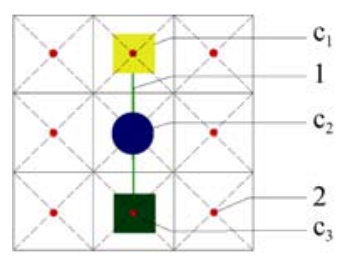

Figure 3 The function of accumulative cost distance model $\mathrm{c}_{\mathrm{i}}$ : cost of cell $i(\mathrm{i}=1,2,3)$; 1: link, and its resistance value is $\left(c_{1}+c_{2}\right) / 2$;

2: node culated, the equation is as follows:

$$
A=\left\{\begin{array}{l}
\frac{1}{2} \sum_{i=1}^{n}\left(c_{i}+c_{i+1}\right) \\
\frac{\sqrt{2}}{2} \sum_{i=1}^{n}\left(c_{i}+c_{i+1}\right)
\end{array}\right.
$$

where $c_{i}$ is the cost value of source cell $i, \mathrm{c}_{i+1}$ is the cost value of target cell, $n$ is the number of cell. When moving from a cell to one of its four directly connected neighbors, it adopts the equation $2 \mathrm{a}$, and if the movement is diagonal, it adopts the equation $2 \mathrm{~b}$.

From this model, it is conceivable that the accumulative cost is the sum of the cost distances from one source to another cell that passes through the cell location. Maybe, there many paths from source to target cell, but there is only one least-cost path which is guaranteed to be the cheapest route from the destination to the source over the cost distance surface.

\section{Data analysis and result}

\subsection{Analysis of landscape pattern}

Landscape pattern change mainly refers to the changes of component, diversity, shape and spatial pattern of landscape along with time. The style, shape, size, number and spatial combination of landscape patch are the result of interaction of disturbance and spatial difference of landscape function, and it affects the ecological process and edge effect of the whole re- 
gion (Farina, 2006). In order to understand characteristics of landscape pattern change in the class-level and landscape-level, some indices were calculated by using Fragatats 3.3. The values of each index at two levels were listed in Tables 1 and 2. In class-level (Table 1), the average contiguity index of urban and building land types has been increasing constantly, whereas for forestland and cultivated land the changes tendency of the average contiguity index presents downtrend basically during 1989-2005. The patch density of forestland, cultivated land, garden plot, urban and building land markedly increases, however, the patch density of the sandy badland and unutilized land shows a distinct reducing trend. Meanwhile, the mean patch area of forestland continually decreases, but the urban and building land shows a rising trend. Although the number of water body patches has been increasing, the mean patch area continuously decreases. It also shows that the patches of the sandy badland reduce most apparently, but it has an increasing trend in the mean patch area from 1989 to 2005. This denotes that the number of the sporadic sandy lands decreases because of the control and restoration of sandy badland. In terms of landscape-level (Table 2), it is found that the number of the patches of the whole landscape in the study area increases by 1482 , and the fragmentation index increases from 6.727 in 1989 to 7.172 in 2005. At the same time the diversity index also increases, indicating that the size of patch tends to be a moderate scale owing to pattern improvement and construction of the region. This calculation can be verified by the change of dominance index, which decreased from 1.174 in 1989 to 1.156 in 2005. It shows the landscape is dominant by several types of landscape. The landscape connectivity index is low, firstly increases and then decreases, but total tendency from 1989 to

Table 1 Landscape structure indices from 1989 to 2005 in northwest of Beijing

\begin{tabular}{llccccccc}
\hline \multirow{2}{*}{ Year } & \multicolumn{1}{c}{ Index } & $\begin{array}{c}\text { Cultivated } \\
\text { land }\end{array}$ & Forestland & $\begin{array}{c}\text { Garden } \\
\text { plot }\end{array}$ & $\begin{array}{c}\text { Sandy } \\
\text { badland }\end{array}$ & $\begin{array}{c}\text { Water } \\
\text { body }\end{array}$ & $\begin{array}{c}\text { Urban and } \\
\text { building land }\end{array}$ & $\begin{array}{c}\text { Unutilized } \\
\text { land }\end{array}$ \\
\hline \multirow{2}{*}{1989} & CONTIG_MN & 0.524 & 0.507 & 0.482 & 0.480 & 0.517 & 0.529 & 0.485 \\
& PD & 1.544 & 0.821 & 0.175 & 1.594 & 0.064 & 0.961 & 1.568 \\
& AREA_MN & 8.093 & 95.99 & 1.179 & 1.377 & 6.405 & 3.64 & 1.499 \\
& SHAPE_MN & 1.333 & 1.348 & 1.199 & 1.226 & 1.281 & 1.311 & 1.249 \\
& CONTIG_MN & 0.453 & 0.462 & 0.416 & 0.413 & 0.452 & 0.424 & 0.447 \\
& PD & 1.731 & 1.211 & 0.159 & 0.701 & 0.124 & 1.825 & 1.122 \\
& AREA_MN & 6.453 & 63.933 & 0.958 & 1.153 & 6.96 & 4.23 & 1.642 \\
& SHAPE_MN & 1.275 & 1.33 & 1.156 & 1.176 & 1.246 & 1.262 & 1.222 \\
& CONTIG_MN & 0.423 & 0.444 & 0.392 & 0.460 & 0.471 & 0.448 & 0.403 \\
& PD & 1.656 & 1.390 & 0.562 & 0.761 & 0.324 & 1.621 & 0.858 \\
& AREA_MN & 4.447 & 56.601 & 0.882 & 1.811 & 3.614 & 6.234 & 0.973 \\
& SHAPE_MN & 1.244 & 1.326 & 1.16 & 1.216 & 1.264 & 1.28 & 1.163 \\
\hline
\end{tabular}

Table 2 Comparison of landscape types diversity, predominance, evenness, fragmentation and connectivity in northwest of Beijing in 1989, 1996 and 2005

\begin{tabular}{ccccccc}
\hline Year & NP & F & SHDI & SHEI & D & C \\
\hline 2005 & 23922 & 7.172 & 0.790 & 0.406 & 1.156 & 0.0082 \\
1996 & 22922 & 6.872 & 0.804 & 0.413 & 1.142 & 0.0065 \\
1989 & 22440 & 6.727 & 0.772 & 0.397 & 1.174 & 0.0090 \\
\hline
\end{tabular}


2005. The urban space expands rapidly, manifesting an obvious expansion trend from suburb to exurb (Figure 1).

\subsection{Problem and perplexity in land use planning by using landscape indices}

A primary goal of landscape ecology is to understand the reciprocal relationship among scale, spatial pattern and ecological flows or processes. Quantitative description of landscape ecological pattern by means of landscape index is the basis for analyzing the landscape structure function and process, and this method has been widely used by most landscape ecological investigators. Unfortunately, based on the quantitative relationship analyses, these indexes calculated in different ways can often reach a deadlock when further explaining the effect of pattern change on certain ecological processes. So how to try to connect landscape metrics with ecological processes at the landscape level and apply them to actual study has become a difficulty and hotspot currently.

In this paper, on the basis of computation of class-level and landscape-level metrics, the law of landscape pattern evolvement was further revealed. It is believed that there were a series of landscape ecological problems caused by city expansion in the past 16 years from 1989 to 2005: landscape ecological connectivity was low, landscape structure was simplified, and the fragmentation of green land patch was more obvious in the plain areas. Moreover, spatial distribution of green land was unbalanced. These results provide scientific and realistic basis for carrying out the optimization design of landscape pattern. However, it is difficult to reveal the key sectors in a specific region, which exerts some significant influences on the safety and healthy of certain. Thus, in the precondition of respecting the nature and conservation of ecological infrastructure, a puzzle is how to apply the method of ecological function flow to identify and build strategic portions and positions of a landscape through optimizing the pattern of landscape in the idiographic space.

\subsection{Landscape pattern optimization}

\subsubsection{Analysis of landscape ecological function}

Ecosystem services imply the natural environmental conditions and their effectiveness formed and sustained by ecosystems and ecological processes (Ouyang, 1999). The key factors that affect the ecosystem service function mainly include land use degree and the inner structure of the ecosystem in a region, where the human activities play the leading role. In this paper, based on the method of ecosystem services assessment which is proposed by Costanza (1998), the spatial difference of landscape function intensity is analyzed through measurement of ecosystem service value of seven landscape types in northeast of Beijing. It is the base for regulating the landscape spatial pattern.

In order to understand spatial difference of landscape function intensity, combined with the characteristics of landscape pattern in the study area, a basal landscape unit (cell) was defined by using the method of image re-classification in GIS environment, and the resolution of each cell was $300 \mathrm{~m} \times 300 \mathrm{~m}$. Subsequently, according to the standard of value assessment of effect of ecosystem, which is proposed by Chen (2000), the value of ecological intensity of landscape cell was obtained by using accumulative cost distance model (Table 3). This result is also the basis for determining the cost coefficient in the process of resistance analysis, and the resistance values of different landscape types depend on the contribution 
rate of land use types to the ecological service. Here we once more make a deep exposition of the concept of landscape resistance, which is described as the effect of spatial pattern impeding the rate of flow of objects, such as species and materials (Forman, 1995).

Table 3 Ecosystem service value of landscape types in northwest of Beijing

\begin{tabular}{|c|c|c|c|}
\hline Landscape type & Area $(\mathrm{hm})$ & Ecosystem service value (million yuan) & Contribution rate $(\%)$ \\
\hline Cultivated land & 66733 & 113 & 4 \\
\hline Forestland & 201247 & 2233 & 77 \\
\hline Garden plot & 6907 & 38 & 1 \\
\hline Sandy badland & 8189 & 0 & 0 \\
\hline Water body & 4870 & 331 & 11 \\
\hline Urban and building land & 39096 & 0 & 0 \\
\hline Unutilized land & 7408 & 175 & 6 \\
\hline
\end{tabular}

From the distribution feature of eco-function intensity cell (Figure 4), we can see that the spatial difference of these landscape ecological function intensity are remarkable in the study area. The highest value of eco-function intensity is in the central mountainous areas and northwestern mountainous areas, and the water area and river landscape dominated areas ranks second. Contrarily, the value of eco-function intensity is lower in plain area, especially in suburb plain area, where the dense road and relatively concentrated built-up areas were distributed. The inhomogeneous distribution of forest landscapes is the main reasons for the spatial difference of eco-function intensity. For example, the mountainous areas with high vegetation coverage are a significant ecological barrier for water and soil conservation as well as wind prevention, while in the plain areas, natural landscapes have been lost due to urban expansion and real estate development, and serious fragmentations are locally occurred, so it is urgent to take measures to improve the connectivity of landscape.

\subsubsection{Identification and construction of strategic landscape elements}

(1) Ecological source region

Based on the theory of spatial ecology, as a landscape type, source landscape contributes positively to the development of the ecological processes. So, we chose water body and large area of green space as the ecological source. In this study, strong special analysis module in GIS was used to complete the extraction of green landscape units (cells), the minimum pixel number of core patch of green landscape was 10 .

(2) Ecological corridor

As a major component of the landscape, a corridor refers to a narrow, linear segment of land that connects ecosystems, green land, water bodies or human activity (Forman and Godron, 1986). Corridors provide protection for the movement of wildlife and plant life across the landscape (ecological corridors), recreational access for rural and urban populations (trails), and enhancement restoration of the damaged ecosystems (i.e. riparian, water body). The connectivity is the essential index to measure connection degree of corridor structure (Farina, 1998). So, strengthening the construction of urban ecological corridor and increasing connection degree of landscape pattern is one of the effective ways to consolidate and strengthen the protective function of ecological barrier of northwestern Beijing.

In GIS environment, supported by the accumulative cost distance model, the accumulative cost distance surface of landscape ecological function was obtained by combining source landscape units and the distribution of eco-function intensity (Figure 5). On this basis, 
the least-cost paths between patches of source landscape were found out, which represents the series of cells which resulted in the lowest cost value for that patch (Figure 6). So, this 'path' can be used as an optimum way or corridor for ecological planning.

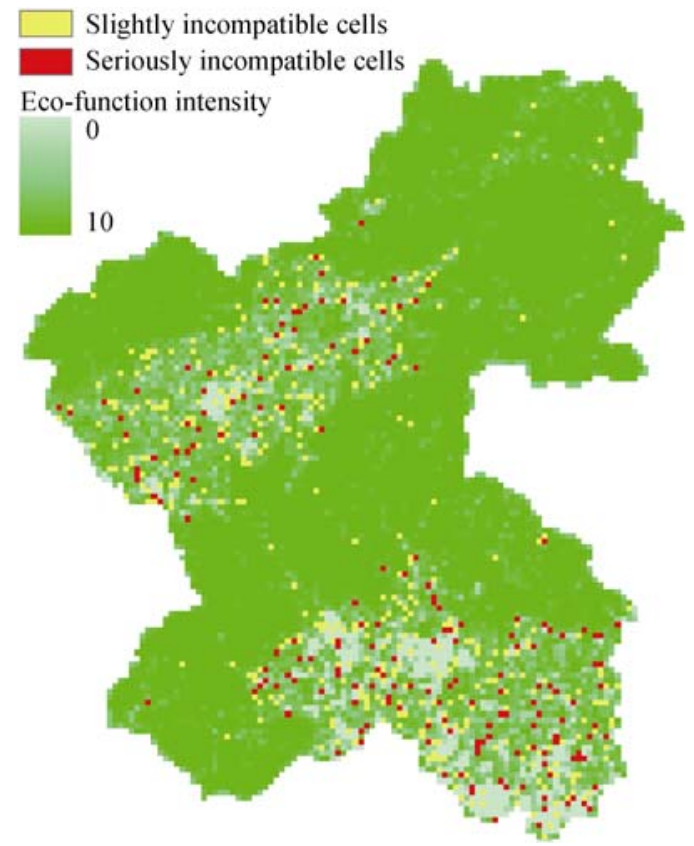

Figure 4 Distribution of eco-function intensity and incompatible cells in northwest of Beijing

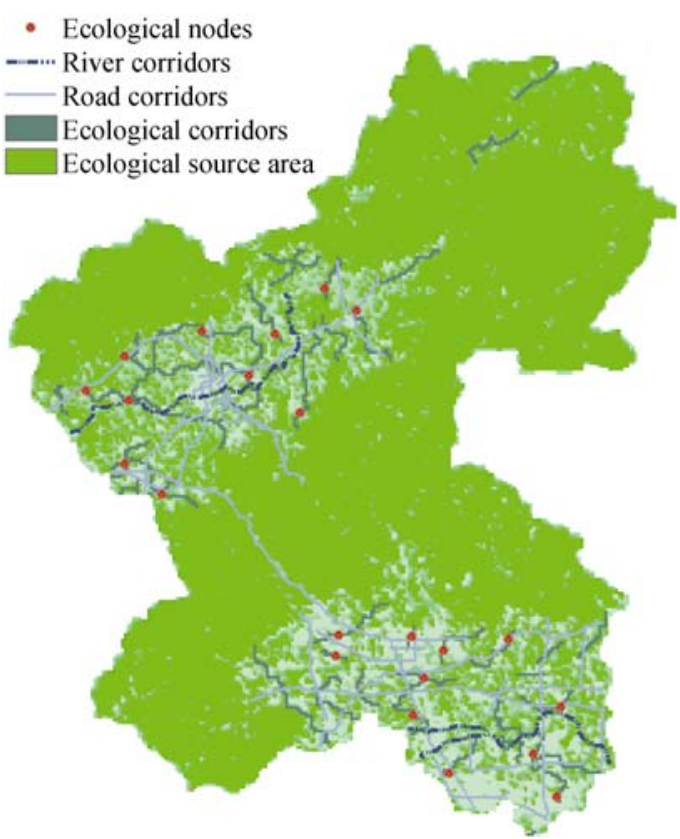

Figure 6 Distribution of elements optimized landscape pattern in northwest of Beijing

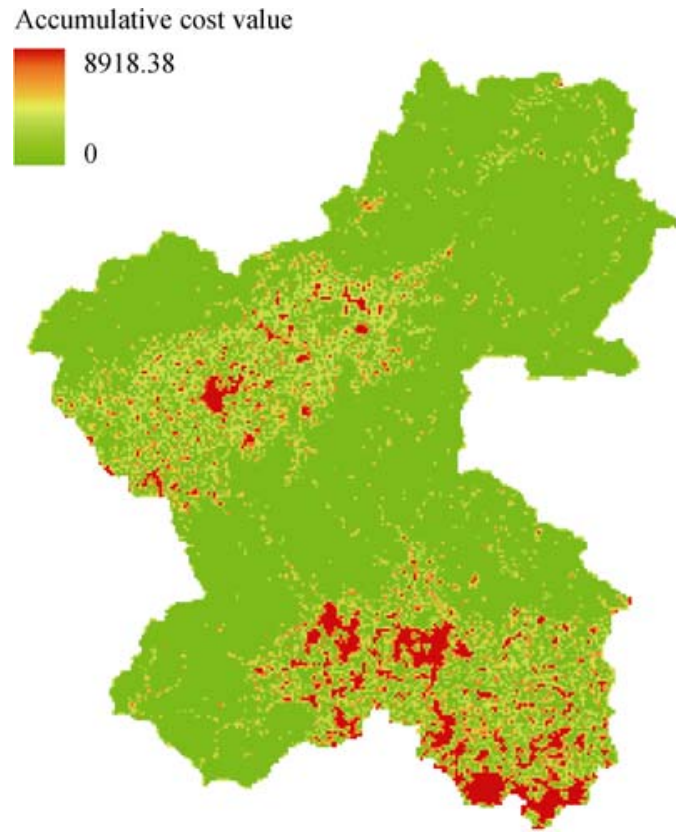

Figure 5 Accumulative cost distance surface in northwest of Beijing

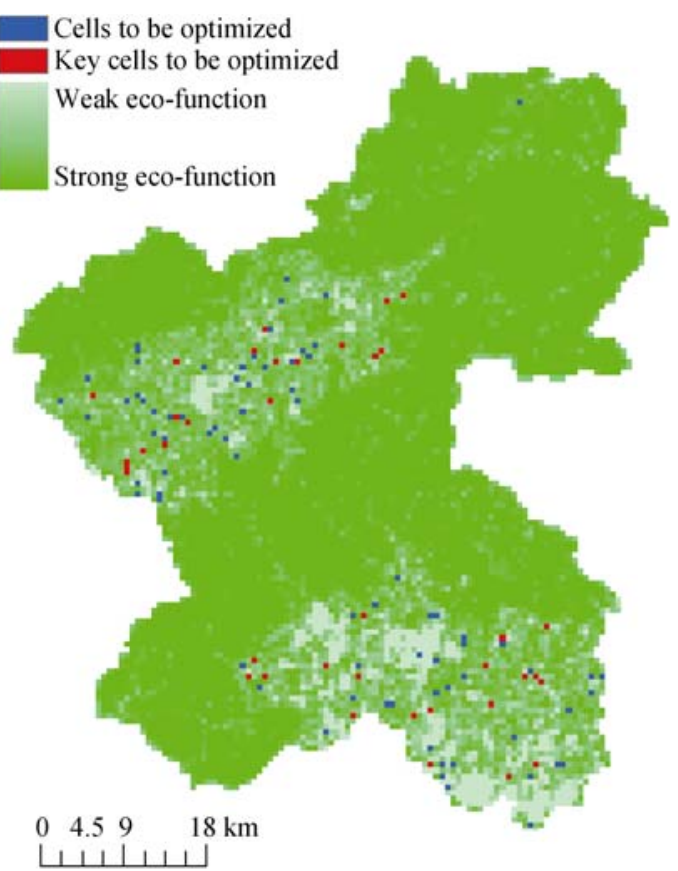

Figure 7 Distribution of cells to be optimized in northwest of Beijing 


\section{(3) Ecological node}

The ecological node is a landscape element used to connect ecological corridors, distributed in the weakest link of eco-function intensity on the corridor where the node stands. This position has important significance for fluency of the ecological flows. Because of large span between two adjacent corridors within a certain spatial distance and external influence, the lack of ecological node has great influence on ecosystem stability and the continuity of process. Therefore, the recognition and establishment of node can help to improve the connectivity of landscape ecological network and to promote healthy development of landscape ecological function. For this reason, we introduced a method of watershed hydrologic analyses into our study with the aid of GIS platform, the intersection point of the least-cost paths and the most-cost paths were worked out, which is the optimum position for the layout of ecological nodes. The distribution of ecological nodes is shown in Figure 6.

\subsubsection{The spatial interaction between various landscape types}

Landscape function is defined as interaction among the spatial elements, i.e., the flow of energy, material, and species among the components of ecosystem (Forman, 1986). The interactions between adjacent landscape elements and landscape edge effect have important influence on landscape function and ecosystem structure. So the landscape resistance can be used to describe the mutual influence between adjacent landscape elements. In general there exists a complementary relation between forest and water body, while urban buildings pose a great threat to ecological function-type landscapes like forest, water body and wetland. In order to avoid incompatibility between different function-type elements in spatial pattern, some landscape elements were planned in the adjoining areas of heterogeneous landscape elements (e.g. grassland and farmland). These landscape types have buffer action to buildings and roads and are helpful to the development of landscape function. In addition, some landscape element patches have a bad effect on other contiguous patches. For instance, the farmlands positioned close to sandy lands are easily subjected to desertification if they are not properly controlled. In order to identify the spatial position of incompatible units and impedimental units, according to the characteristics of the landscape components, this paper analyzed the accumulative cost surface by using the GIS spatial analysis tools, and the grid cells of the maximum cost value and minimum cost value were differentiated from different land cover types and landscape elements through selecting a suitable threshold (Figure 4).

\subsubsection{The overall scheme of landscape pattern optimization}

Landscape pattern optimization aims to construct a more reasonable land-use pattern, which is beneficial to the development of ecological processes. As the above results suggest, landscape fragmentation and low connectivity caused by urbanization process is the main crux of the problem. Changes in connectivity are mainly due to changes in linear elements. So, in the design and implementation of optimization scheme, it's necessary to protect the ecological source land (e.g. forestland and water body), build ecological corridors and nodes, and perfect the ecological network. The concrete optimum scheme is as follows:

(1) Identification and conservation of the ecological source

Based on the research scale, the minimum area of source patch was determined as 90,000 $\mathrm{m}^{2}$, which corresponds to the total area of 10 pixels of $30 \mathrm{~m} \times 30 \mathrm{~m}$. Under the guidance of the methods of combining green landscape of the region with the virtual landscape of this study, the ecological source landscape is mainly composed of five parts: mountain areas with 
high vegetation coverage, suburb forest parks (mainly includes Lianhuashan forest park, Songshan forest park, Shuanglongshan forest park, etc.), some large scenery spots (mainly includes Longqingxia, Xigou, Yudushan, etc.), large reservoirs (mainly includes Shisanling reservoir, Taoyukou reservoir, Shahe reservoir, etc.) and some combined green belts in plain area of northwest of Beijing. Those source landscape elements play an important role in controlling and promoting the stability of ecological function in the region. For ecological construction and protection of eco-sources, it is essential to increase the area of core patches and enhance heterogeneity of source landscapes.

(2) Planning and construction of the ecological corridors

Ecological corridor is the main channel for the dispersal of species and the flows of material and energy between the eco-source patches. In this paper, planning and construction of the ecological corridors should follow the results obtained from the accumulative cost distance model, and hold on the idea of designing with nature. It is suggested that the width of ecological corridor should be controlled in an appropriate range, thus, the minimum widths of main ecological corridor is $300 \mathrm{~m}$, which is corresponding to the spatial distance of the small area source patches. A buffer belt with a certain width was formulated in order to enhance ecological effect of corridors and coping with the shocks of urban expansion. Besides, according to distribution characteristics of roads and rivers in this region, the relevant planning was advanced, and its main goal is to reinforce the ecological protection capability of corridor landscapes, especially river corridor (Figure 6).

(3) Construction of the ecological node

The ecological node is the intersection point of minimum cost path and maximum cost path on the medium surface. In this paper, the ecological nodes were built by the application of GIS spatial tools, which are distributed on 22 different positions (Figure 6). The eco-source regions are connected by the eco-corridors, the eco-corridors are connected by the eco-nodes, and they form a complete landscape eco-network, through which different ecosystems are linked in study area. So the construction of these nodes will strongly promote the development of landscape ecological function.

In order to provide practical instructions for landscape ecological construction, based on the results obtained in this study, according to the spatial distribution characteristics and severity degree of incompatible landscape units (cells), the cells and key cells to be optimized were determined. Figure 7 shows that these cells were subjected to substantial shock caused by other hard landscapes such as buildings, roads and sandy land, therefore, it is very necessary to change the use patterns of the cells and make them optimized to tackle with direct adjacency between ecological function-type landscapes and other hard landscapes.

\section{Conclusions and discussion}

As already argued by other authors (Walker and Craighead, 1997; Yu, 1999), this study shows that the accumulative cost distance model is a useful research tool to understand the interrelation between ecological function and landscape patterns, crucial to design land-use strategies. It is also an interesting tool for predicting the effect of pattern changes in the landscape on connectivity in a quantitative way. This modeling mainly considers source, distance and landscape resistance, and obtains insights into the spatial variation features of landscape flows. It endows the general mean of landscape with a certain meaning of process. 
In this paper, by means of the method of landscape pattern index analysis, the change characteristics of the pattern were analyzed. The results showed that landscape structure was simplified, and the fragmentation of green land patch was more obvious in the plain areas. Moreover, spatial distribution of green land was unbalanced. It is believed that the cause of the problems is due to the urban disorder expansion in the past 16 years (1989-2005). Extremely low landscape connectivity has a strong impact on the development of eco-function.

As a whole, through the analysis of landscape structure, the results are significant to understanding the essence of landscape pattern evolvement. Although the landscape metrics analysis is a simple and flexible method for monitoring and predicting landscape changes, now, it is quite difficult to solve problems of irrational landscape patterns such as incompatible landscape units and low landscape connectivity. Therefore, supported by the theory of landscape resistance to flow or movement of energy, material, and disturbance over a landscape and GIS technology, an overall scheme of landscape pattern optimization was proposed through analysis of landscape ecological function. In view of landscape connectivity problem in a complex landscape, by using the accumulative cost distance modeling to identify and build some critical landscape elements such as ecological sources, ecological corridors and nodes, a optimal plan was proposed, which can effectively enhance integrity and association among various elements. The methods and final results in this study are expected to be useful for urban ecological planning and sustainable use of land resource in northwest of Beijing, China.

In the process of urbanization, the irrational land use activities are the main cause of landscape spatial differentiation, and further affect on benign circulation of regional ecosystem. Thus, in order to realize the sustainable development of ecological environment, how to design and build an optimized spatial pattern which can not only meet the demand for living and developing of human beings but also can maintain the ecosystem integrity in certain landscape scale has been a commonly concerned problem for ecologists, land managers, and planners. From the angle of landscape function, this paper explored a path for planning some key elements and the least-cost paths based on landscape ecology, which provided a new way to support the research on landscape ecological planning for ecologists. However, this study is not yet perfect. Firstly, it is necessary to determine the optimal scale for ecological planning due to the scale dependence for some ecological process. Secondly, the use of this model needs a more detailed index system of landscape elements and appropriate method of evaluating on ecological functions. Thirdly, because of complicated relationship among landscape patterns, functions and ecological processes, many factors have not been taken into account, so there are something left behind for us to find out in method and theory. In addition, it is worthwhile to mention that the GIS and RS have wide application prospects in landscape pattern optimization based on ecological methods.

\section{References}

Adriaensen F, Chardon J P, Blust G D et al., 2003. The application of 'least-cost' modeling as a functional landscape model. Landscape and Urban Planning, 64: 233-247.

Cao Xinxiang, Ding Shengyan, 2005. Landscape pattern dynamics of water body in Kaifeng city in the 20th century. Journal of Geographical Sciences, 15(1): 106-114.

Chen Liding, Fu Bojie, Zhao Wenwu, 2006. Source-sink landscape theory and its ecological significance. Acta Ecologica Sinica, 26(5): 1444-1449. (in Chinese) 
Chen Zhongxin, Zhang Xinshi, 2000. Values of ecosystem effects in China. Chinese Science Bulletin, 45(1): 17-22. (in Chinese)

Costanza R, d'Arge R, Groot R D et al., 1998. The value of the world's ecosystem services and natural capital. Ecological Economics, 25: 3-15.

Doing H, 1997. The landscape as an ecosystem. Agriculture, Ecosystems and Environment, 63: 221-225. (in Chinese)

Farina A, 2006. Principles and Method in Landscape Ecology. London: Chapman and Hall.

Forman R T T, 1995. Land Mosaics: The Ecology of Landscapes and Regions. Cambridge: Cambridge University Press.

Forman R T T, Godron M, 1986. Landscape Ecology. New York: John Wiley \& Sons.

Fu Bojie, Gulinck H, 1994. Land evaluation in area of severe erosion: The Loess Plateau of China. Land Degradation \& Rehabilitation, 15(1): 33-40.

Han Wenquan, Chang Yu, Hu Yuanman et al., 2005. Research advance in landscape pattern optimization. Chinese Journal of Ecology, 24(12): 1487-1492. (in Chinese)

He Yanfen, Zhang Bai, Liu Zhiming, 2007. Study on the impact of landscape pattern and dynamic change on agricultural drought disaster. System Sciences and Comprehensive Studies in Agriculture, 23(1): 69-73. (in Chinese)

Hof J, Flather C, 2004. Optimization of landscape pattern. In: Wu J, Hobbs R (eds.). Key Topics and Perspectives in Landscape Ecology. Cambridge: Cambridge University Press.

Kang Muyi, Yao Huarong, Liu Shuo, 1999. Land use structure optimization for Guanzhong Region, Shaanxi Province. Journal of Natural Resources, 14(4): 363-367. (in Chinese)

McGarigal K, Marks B, 1995. FRAGSTATS: Spatial pattern analysis program for quantifying landscape structure. Gen. Tech. Rep. PNW-GTR-35. USDA, Forest Service, Pacific, Northwest Research Station, Portland.

O'Neil R V, Krummel J R, Gardner R H et al., 1988. Indices of landscape pattern. Landscape Ecology, 1(3): $153-162$.

Seppelt R, Voinov A, 2002. Optimization methodology for land use patterns using spatially explicit landscape models. Ecol. Model., 151: 125-142.

Seppelt R, Voinov A, 2003. Optimization methodology for land use patterns: Evaluation based on muhiscah habitat pattern comparison. Ecol. Model., 168: 217-231.

Thomas M R, 2002. A GIS-based decision support system for Brownfield redevelopment. Landscape and Urban Planning, 58(1): 7-23.

Turner M G., 1989. Landscape ecology: The effect of pattern on process. Annual Review of Ecology and Systematics, 20: 171-197.

Turner M G, Romme W H, Gardner R H et al., 1993. A revised concept of landscape equilibrium: Disturbance and stability on scaled landscapes. Landscape Ecology, 8: 213-227.

Vincent J Burke, 2000. Landscape ecology and species conservancy. Landscape Ecology, 15(1): 1-3.

Walker R, Craighead L, 1997. In: Proceedings of the ESRI European User Conference on Analyzing Wildlife Movement Corridors in Montana Using GIS, Copenhagen, 1-18.

Wu Jianguo, Hobbs R, 2002. Key issue and research priorities in landscape ecology: An idiosyncratic synthesis. Landscape Ecol., 17: 355-365.

Xiao Duning, Li Xiuzhen, 1999. The Development and Perspective of Contemporary Landscape Ecology: Progress in Landscape Ecology. Changsha: Hunan Science and Technology Press, 1-7. (in Chinese)

Yu Kongjian, 1999. Landscape ecological security patterns in biological conservation. Acta Ecologica Sinica, 19(1): 8-15. (in Chinese)

Yu Kongjian, Li Dihua, 1997. Landscape ecological modes in urban-suburban and area planning. Foreign Urban Planning, (3): 27-31.

Yuan Yi, Shi Peijun, Liu Yinghui et al., 2003. A study on the pattern of land cover during rapid urbanization: Shenzhen City as a case study. Acta Ecologica Sinica, 23(9): 1832-1840. (in Chinese)

Zeng Hui, Jiang Chuanming, 2000. Structure study of Longhua area in Shenzhen City during the fast urbanization process: Structure and heterogeneity analysis of forest land. Acta Ecologica Sinica, 20(3): 378-383. (in Chinese) 